\title{
Global drivers of future river flood risk
}

\author{
Hessel C. Winsemius ${ }^{1 \star}$, Jeroen C. J. H. Aerts ${ }^{2,3}$, Ludovicus P. H. van Beek ${ }^{4}$, Marc F. P. Bierkens ${ }^{1,4}$, \\ Arno Bouwman ${ }^{5}$, Brenden Jongman ${ }^{2,3}$, Jaap C. J. Kwadijk ${ }^{1,6}$, Willem Ligtvoet ${ }^{5}$, Paul L. Lucas ${ }^{5}$, \\ Detlef P. van Vuuren ${ }^{5,7}$ and Philip J. Ward ${ }^{2,3}$
}

\begin{abstract}
Understanding global future river flood risk is a prerequisite for the quantification of climate change impacts and planning effective adaptation strategies ${ }^{1}$. Existing global flood risk projections fail to integrate the combined dynamics of expected socio-economic development and climate change. We present the first global future river flood risk projections that separate the impacts of climate change and socio-economic development. The projections are based on an ensemble of climate model outputs ${ }^{2}$, socio-economic scenarios ${ }^{3}$, and a state-of-the-art hydrologic river flood model combined with socio-economic impact models ${ }^{4,5}$. Globally, absolute damage may increase by up to a factor of 20 by the end of the century without action. Countries in Southeast Asia face a severe increase in flood risk. Although climate change contributes significantly to the increase in risk in Southeast Asia ${ }^{6}$, we show that it is dwarfed by the effect of socio-economic growth, even after normalization for gross domestic product (GDP) growth. African countries face a strong increase in risk mainly due to socio-economic change. However, when normalized to GDP, climate change becomes by far the strongest driver. Both highand low-income countries may benefit greatly from investing in adaptation measures, for which our analysis provides a basis.
\end{abstract}

Between 1980 and 2013, the global direct economic losses due to floods exceeded $\$ 1$ trillion (2013 values), and more than 220,000 people lost their lives ${ }^{7}$. Global flood damages have been increasing steeply over the past decades, so far mainly driven by steady growth in population and economic activities in flood-prone areas ${ }^{8,9}$. Future increases in flood frequency and severity due to changes in extreme weather are expected ${ }^{1,9}$. Such increasing trends in flood risk may have severe direct humanitarian and economic impacts and lasting long-term negative effects on economic growth ${ }^{10,11}$. In 2015, several major international policies are being initiated or renewed that may catalyse flood risk adaptation and hence risk reduction, such as the Sustainable Development Goals, Conference of the Parties (COP) 21, and the Sendai Framework for Disaster Risk Reduction. Such efforts require global understanding of the drivers of flood risk change in the future.

Past efforts to enhance this understanding have focused on the global-scale mapping of present-day flood hazard ${ }^{12,13}$ and risk ${ }^{4,5}$ and future changes in global flood exposure and risk ${ }^{14}$ due to either climate change $e^{6,15,16}$ or socio-economic development ${ }^{8,17}$. One recent study ${ }^{18}$ combined global socio-economic and climate change into future global flood risk projections for the first time, however, this work did not reveal regional patterns nor quantify the drivers of risk change. Furthermore, no study has so far accounted for installed and maintained flood protection standards (FPS; ref. 10).
Here, we significantly enhance the global-scale understanding of river flood risks and provide estimates of global changes in economic damage throughout the twenty-first century (2030 and 2080). We show how flood risk may evolve in the case that no further investments are made to reduce flood risks. This analysis flags how important flood risk management is to keep risks at an acceptable level. First, we show transparently how much of the change in risk originates from socio-economic change and how much from climate change. Second, we normalize estimates of urban economic damage to regional GDP, which provides important information on the economic impact of the damages. Growing economies result in increasing damage levels but also allow for a more effective management and financial absorption of the damages ${ }^{19,20}$. Third, besides climate change and socio-economic change, we illustrate the possible impact of adaptation measures, expressed in the level of FPS, on global flood risk.

Our model framework, described in Supplementary Sections 1 and 2, estimates current and future annual averaged urban flood damage from large-scale river flooding (rivers with basin sizes of the order of about $10,000 \mathrm{~km}^{2}$ and larger) based on several return period conditions. The framework can incorporate estimates of FPS (further described in Supplementary Section 6). Uncertainties in the extreme value distribution of flooding are propagated in the present-day flood risk estimates, to assess the significance of the relative risk change estimates at the basin scale. To demonstrate that currently installed flood protection is an important missing link in the assessment of global flood risk, we assessed flood risk under the assumptions of 'No FPS'; and of 'Partial FPS', where high-income countries are protected against 100-year floods (that is, floods occurring on average once every 100 years) and all others against 5-year flood events. We performed historical runs with a reanalysis dataset and present-day GDP estimates, and future runs with bias-corrected outputs from an ensemble of global circulation models (GCMs) participating in the Climate Model Intercomparison Project Phase 5 (CMIP5) (ref. 21), forced with a number of Representative Concentration Pathways ${ }^{22}$ (RCP) and downscaled socio-economic scenarios from the Shared Socioeconomic Pathways ${ }^{3}$ (SSP). Three scenario combinations were chosen: 'Sustainability' (SSP1, combined with RCP2.6), 'Fragmented world' (SSP3, combined with RCP6.0) and 'Fossil fuel-based development' (SSP5, combined with RCP8.5). The scenarios are further described in Supplementary Section 1. The multi-model mean hazard change estimates are shown in Supplementary Figs 1-4 for all RCPs. Furthermore, we assess the GCM uncertainty by showing the range in GCM outputs across different income regions. Note that the presented estimates of relative changes in risk are more

\footnotetext{
${ }^{1}$ Deltares, 2629 HV Delft, The Netherlands. ${ }^{2}$ Institute for Environmental Studies (IVM), Vrije Universiteit Amsterdam, 1081 HV Amsterdam, The Netherlands. ${ }^{3}$ Amsterdam Global Change Institute (AGCI), Vrije Universiteit Amsterdam, 1081 HV Amsterdam, The Netherlands. ${ }^{4}$ Department of Physical Geography, Utrecht University, 3508 TC Utrecht, The Netherlands. ${ }^{5}$ PBL Netherlands Environmental Assessment Agency, 3721 MA Bilthoven, The Netherlands. ${ }^{6}$ Twente Water Centre, University of Twente, 7500 AE Enschede, The Netherlands. ${ }^{7}$ Copernicus Institute for Sustainable Development, Utrecht University, 3508 TC Utrecht, The Netherlands. *e-mail: hessel.winsemius@deltares.nl
} 
a
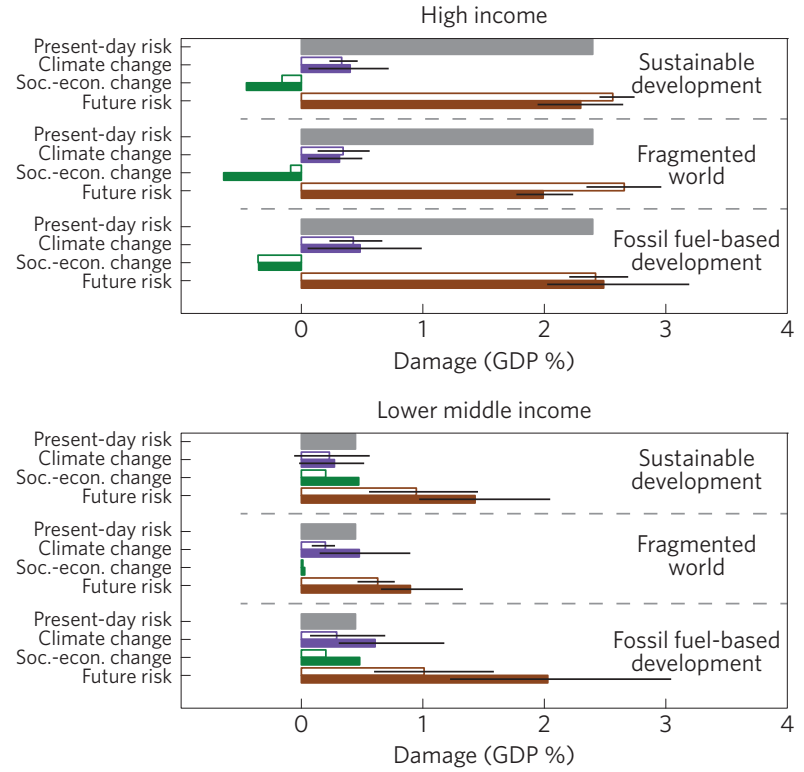

e

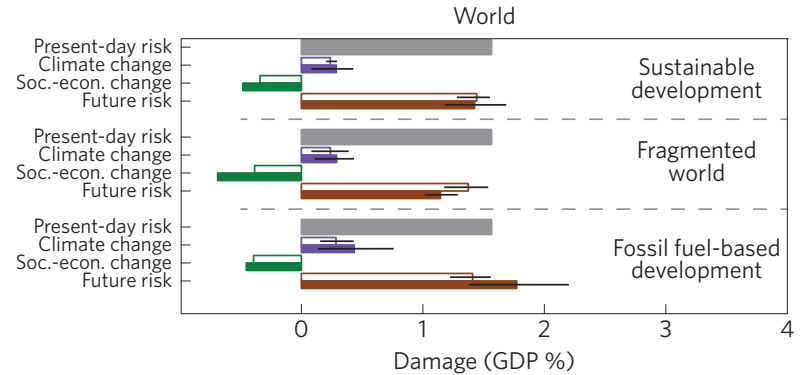

b
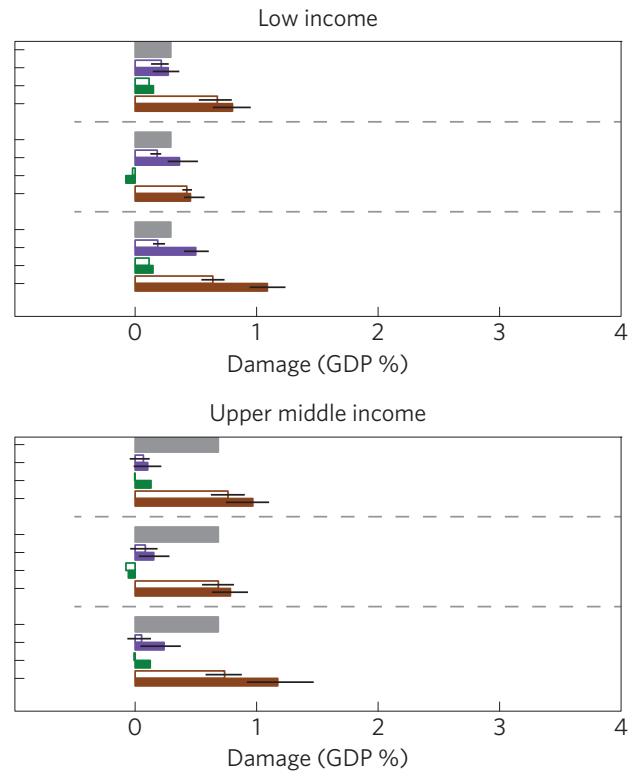

Figure 1 | Changes in economic risk under 'No FPS' conditions, expressed as annual average urban damage as a percentage of GDP. a-e, Damage for high (a), low (b), lower middle (c) and upper middle (d) income bands. e, Total global damage. Grey bars show the present-day risk level. Purple and green bars show the contribution of climate change and economic growth patterns to risk changes respectively. Brown bars show the resulting risk in the future. Open bars show the risk changes and total risk in 2030 while closed bars show risk changes and total risk in 2080.

robust than the absolute risk estimates. This is further explained in Supplementary Section 7.

Assuming 'No FPS', our computations (Supplementary Table 1) show that under the 'Fossil fuel-based development' projection, global economic urban damage per year increases from over US1 trillion currently, up to a maximum of US\$ 13.7 trillion in 2080 (11.1 to 17.0 GCM range), a more than 10-fold increase compared with 2010. Under 'Partial FPS', this estimate lowers to US\$ 4.4 trillion per year (3.2 to 5.2 GCM range) showing the effectiveness of FPS. But in relative numbers, the increase in risk is larger, that is, at least 20-fold compared with 2010. This stronger relative increase compared with the analysis without FPS is because the risk is composed of higher return period events, which are subject to larger increases in the future than lower return period events. In both cases, the increase is largely (66-87\% scenario dependent) due to rapid increase in GDP across all world regions. As this will also increase the ability to cope with losses, we turn to the ratio of urban damage to GDP as a proxy for economic impact. This is shown in Fig. 1 for 'No FPS' and Fig. 2 for 'Partial FPS', with more detailed results shown in Table 1 and GCM specific calculations delivered in Supplementary Data 1. A present-day annual damage without FPS would amount to about $1.6 \%$ of global GDP. This number reduces to $0.25 \%$ when considering 'Partial FPS' in the computations (Fig. 2, grey bars in panel e), which is much more consistent with reported damage to GDP ratios due to river flooding: between 1980 and 2010 these are estimated at $0.12 \%$ of GDP globally with a large uncertainty (standard deviation $0.11 \%$; computations based on ref. 7 and GDP data from the World Bank). Residual differences with our model results may be related to uncertainties in the modelling chain; the fact that not all damages are reported ${ }^{23}$; and inaccuracies surrounding our FPS estimates (see Supplementary Section 7).

The scenarios show that without FPS, risk normalized to GDP reduces slightly in 2 out of 3 scenarios ('Sustainability' and 'Fragmented World') from about $1.6 \%$ to about $1.4 \%$ (1.22 to 1.56 GCM range) in 2030 (see Table 1). In 2080, the reduction in risk in the 'Fragmented World' falls to $1.14 \%$ (1.0 to $1.28 \mathrm{GCM}$ range) of GDP. This global reduction can be explained by the fact that most GDP growth is projected to take place in areas that (without accounting for FPS) have a present-day and future damage normalized to GDP that is far below the global average. When FPS is accounted for, the composition of the global average changes, resulting in an increase in risk from $0.25 \%$ of global GDP to $0.32 \%$ ('Fragmented World', 0.26 to 0.35 GCM range), up to $0.57 \%$ ('Fossil fuel-based development', GCM range 0.42 to 0.67 ), that is, an increase of a factor 1.3 to 2.3. Global risks (\% GDP) increase the least in the 'Fragmented World' scenario, because of its lower projected economic growth in lower to upper middle income countries, leading to a lower impact of socio-economic change on risk change (green bar in Figs 1 and 2b,c).

Turning to the individual income regions (Figs $1 \mathrm{a}-\mathrm{d}$ and $2 \mathrm{a}-\mathrm{d}$ ), damage normalized to GDP in high-income countries remains quite stable across all projections and for both FPS assumptions, whereas it increases in all other income regions. In high-income regions, socio-economic change may lead to a significant reduction in damage normalized to GDP (green bars in Figs 1 and 2a), which balances possible future increases in hazard due to climate change 
Table 1 | Future projections of economic impact (measured as the ratio of urban damage to GDP).

\begin{tabular}{|c|c|c|c|c|}
\hline Income region* & Present day (\%) & Sustainability (\%) & Fragmented world (\%) & Fossil-fuel-based development (\%) \\
\hline \multicolumn{5}{|c|}{ Projections for 2030 (No FPS) } \\
\hline High income & 2.40 & 2.56 & 2.66 & 2.42 \\
\hline Low income & 0.29 & 0.68 & 0.43 & 0.64 \\
\hline Lower middle income & 0.45 & 0.95 & 0.63 & 1.01 \\
\hline Upper middle income & 0.68 & 0.76 & 0.69 & 0.74 \\
\hline World average & 1.57 & 1.44 & 1.37 & 1.41 \\
\hline \multicolumn{5}{|c|}{ Projections for 2080 (No FPS) } \\
\hline High income & 2.40 & 2.30 & 1.99 & 2.49 \\
\hline Low income & 0.29 & 0.80 & 0.46 & 1.09 \\
\hline Lower middle income & 0.45 & 1.43 & 0.90 & 2.03 \\
\hline Upper middle income & 0.68 & 0.97 & 0.78 & 1.17 \\
\hline World average & 1.57 & 1.43 & 1.14 & 1.77 \\
\hline \multicolumn{5}{|c|}{ Projections for 2030 (Partial FPS) } \\
\hline High income & 0.12 & 0.13 & 0.13 & 0.12 \\
\hline Low income & 0.18 & 0.36 & 0.23 & 0.34 \\
\hline Lower middle income & 0.28 & 0.48 & 0.33 & 0.51 \\
\hline Upper middle income & 0.42 & 0.44 & 0.40 & 0.43 \\
\hline World average & 0.25 & 0.34 & 0.29 & 0.33 \\
\hline \multicolumn{5}{|c|}{ Projections for 2080 (Partial FPS) } \\
\hline High income & 0.12 & 0.11 & 0.10 & 0.12 \\
\hline Low income & 0.18 & 0.40 & 0.22 & 0.50 \\
\hline Lower middle income & 0.28 & 0.71 & 0.41 & 0.88 \\
\hline Upper middle income & 0.42 & 0.55 & 0.43 & 0.61 \\
\hline World average & 0.25 & 0.48 & 0.32 & 0.57 \\
\hline
\end{tabular}

The left column shows the current risk (climate 1960-1999, population 2010). All other columns show the different projections. The first two sections show the results under 'No FPS' conditions, the bottom two show results under 'Partial FPS' conditions. *Based on the World Bank income classifications ${ }^{27}$.

a

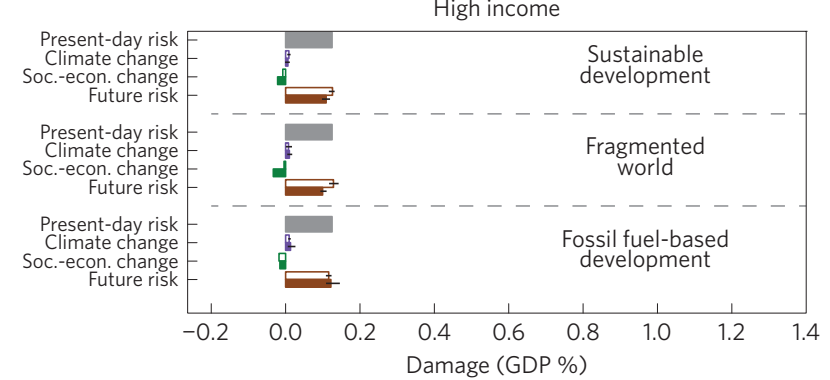

c

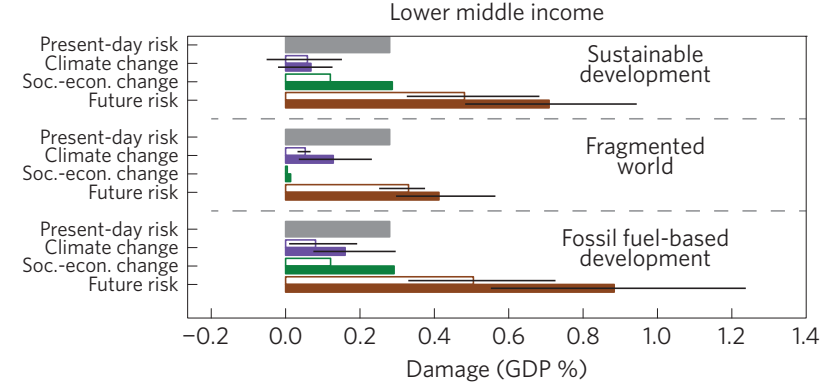

e

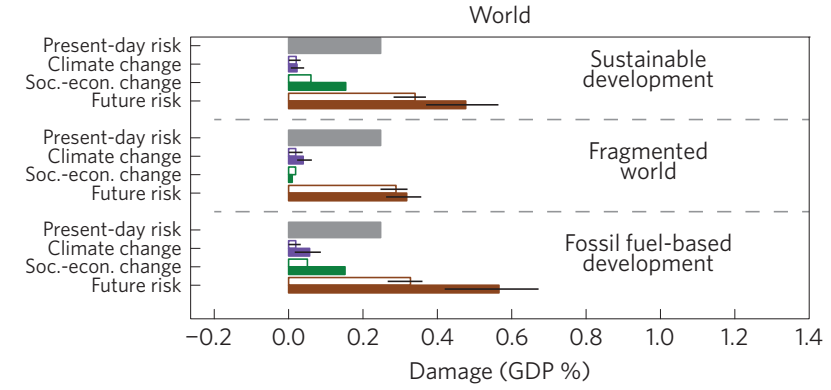

b

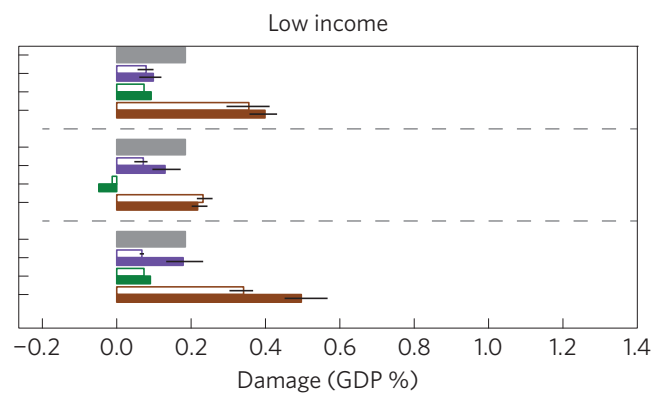

d

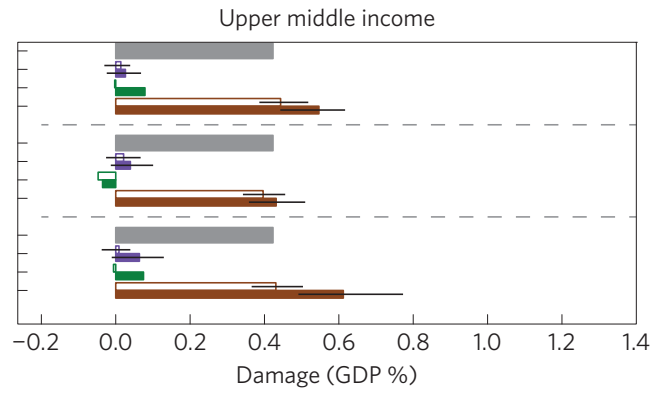

Present day

Climate change 2010-2030

Climate change 2010-2080

$\square$ Socio-economic change 2010-2030

Socio-economic change 2010-2080

Total change 2010-2030

Total change 2010-2080

- GCM range

Figure 2 | Same as Fig. 1 but under 'Partial FPS' conditions. 


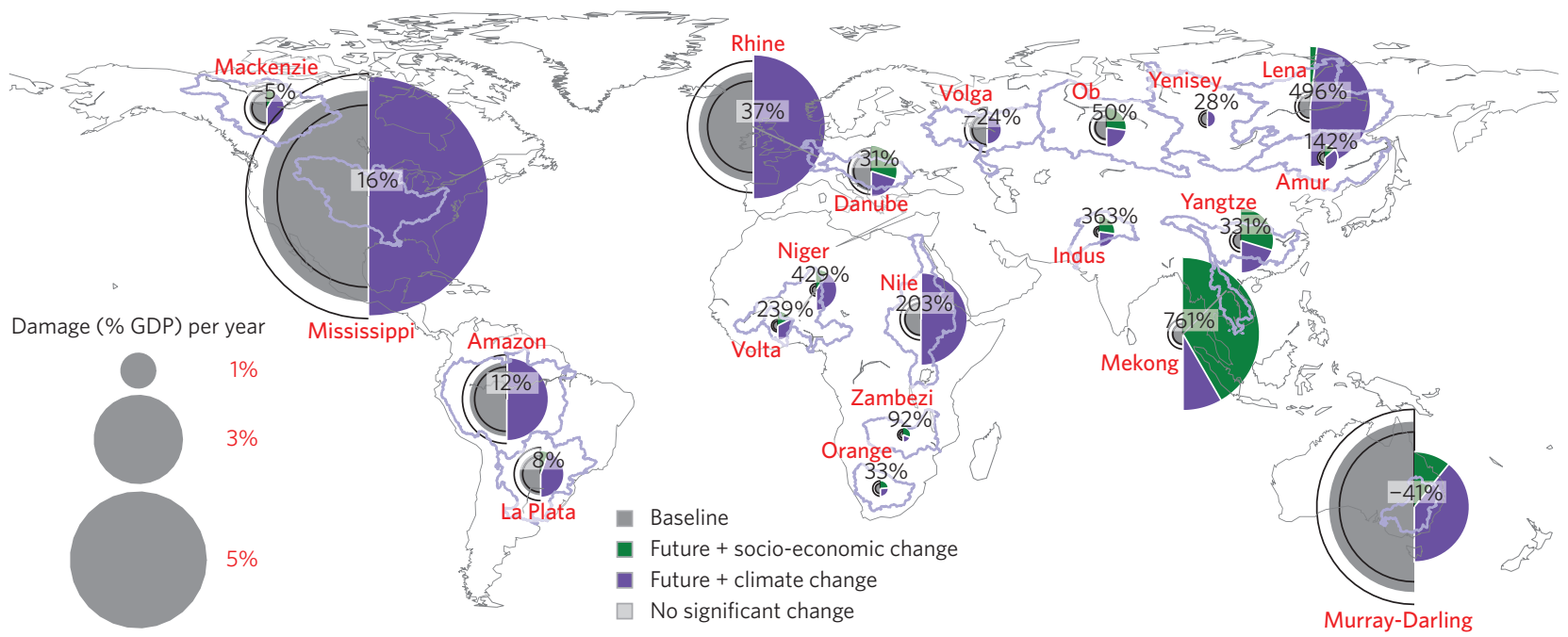

b

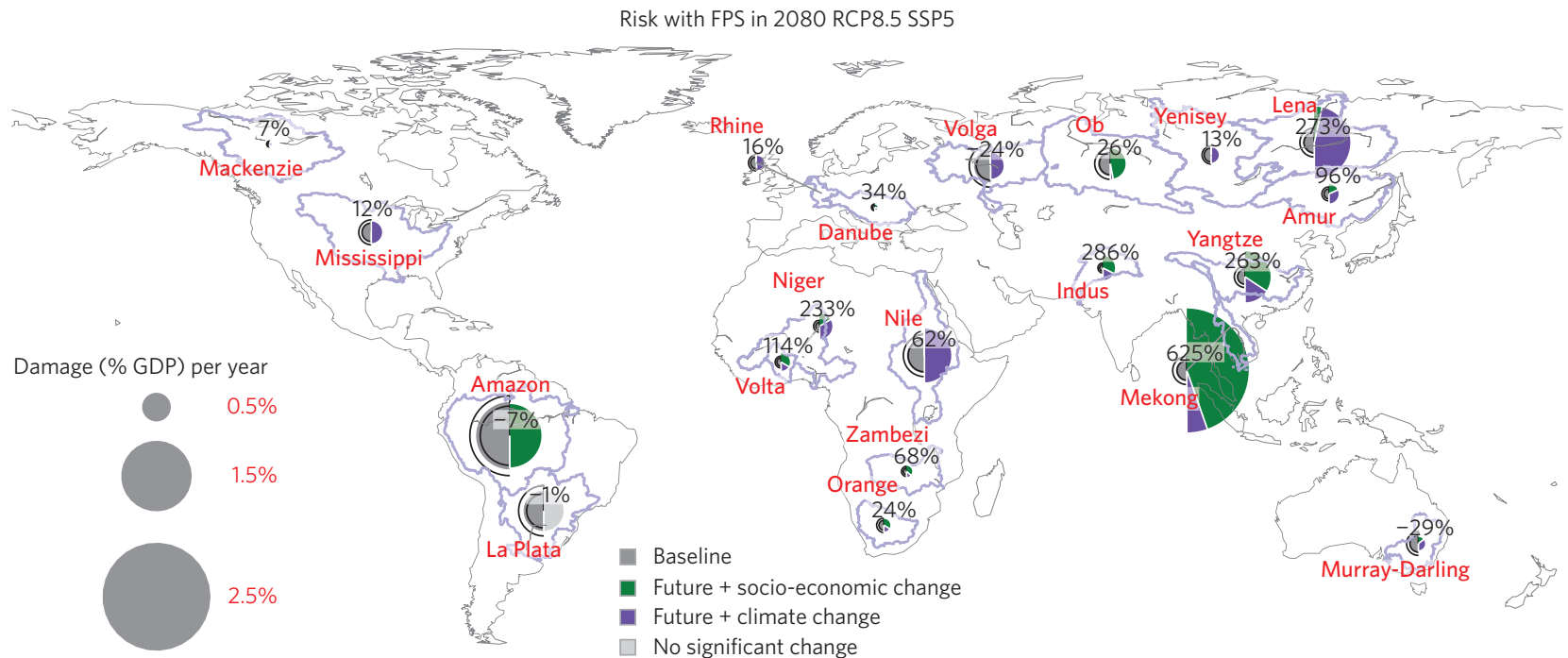

Figure $\mathbf{3}$ | Projected change in economic risk until 2080 in the 'Fossil fuel-based development' projection. a, The ratio of annual urban damage over the basin's total GDP per year under 'No FPS' conditions. $\mathbf{b}$, Same as a but for 'Partial FPS' conditions. Note that the scales of the circular diagrams of a,b are different due to the large difference between 'No FPS' and 'Partial FPS' conditions. The grey left halves of the circles represent the current risk, with estimated uncertainty bounds in black lines (see Supplementary Section 1 for the uncertainty bound estimation). The right half of the circles represents future risk. The relative sizes of the two different colours represent the relative contributions of climate change and socio-economic change to risk increases or decreases. The percentage for each basin indicates the increase in the risk metric displayed from the present day (2010) to 2080.

(pink bars in Figs 1 and 2a). Most increase is found in the 'fossil fuel-based development' projection in the lower middle income region (growing from $0.45 \%$ for the present day to $1.0 \%$ and $2.0 \%$ of GDP in 2030 and 2080, respectively, without FPS, and from $0.28 \%$ to $0.51 \%$ and $0.88 \%$ with FPS) with a large range of results, attributable to the differences between the GCM outcomes. These increases, however, are mostly due to socio-economic change and can be explained by the fact that in lower- to upper-income regions the SSP scenarios show disproportionate economic growth in cities in flood-prone areas. Our estimates of future urban damage depend on the increase (or decrease) in population and relative growth of urban density, and consequently, urban capital (see Supplementary Section 1). In high-income regions, urban density is reaching its upper limits and a population decline is projected (in particular in the 'Fragmented world' projection), explaining the decreasing impact of socio-economic changes. In low-income regions, climate change contributes significantly to risk increase and this signal is very robust among the different outcomes of the GCMs.
Figure 3 shows the basin-averaged damage normalized to GDP in 2080 for the SSP 'Fossil fuel-based development' for a number of large river basins. The figure corroborates that-if FPS are not accounted for-even present-day risk would be highest in highincome regions, such as the Rhine and Mississippi basins. With FPS, the risk would concentrate much more in basins in lower middleincome regions such as the Yangtze, Mekong and Lena basins (with the Lena undergoing a major impact of climate change). The figures reveal large geographical differences in the drivers of increased risk throughout the twenty-first century. Basins in heavily urbanized regions and emerging economies (for example, the Mississippi, Rhine, Danube, Yangtze and Mekong basins) are projected to face an increase in the economic impacts of river floods, although the changes are in some cases less significant under model uncertainty: in the heavily urbanized regions, most of this increase (with FPS) is quite moderate (for example, for the Rhine this is a $16 \%$ rise by 2080 in the 'Fossil-fuel-based development' projection), and changes can be largely attributed to climate change (in particular for 
the Mississippi and Rhine basins). This confirms the results found for the different income region averages. In the growing economies in Southeast Asia (for example, the Indus, Yangtze and Mekong basins), the risk growth is much larger (over a factor of six in the Mekong under 'Fossil fuel-based development') and although climate change plays a significant role in this increase (as already shown in earlier studies ${ }^{6}$ ) its effect is dwarfed by the impact of the more rapid growth of economic activities in urban areas. This growth is consistent with earlier global flood exposure studies ${ }^{8}$ and is highly robust across all three scenarios (further shown in Supplementary Figs 9 and 10). Finally, in regions in Africa above the equator, we simulate large risk increases expressed as damage normalized to GDP (for the Nile, Niger and Volta basins) that are to a large degree driven by climate change.

We show that global economic damages increase faster than global economic wealth (shown through the damage to GDP ratio). This increasing burden of flood damage on the global economy calls for further adaptation. The increasing risks may affect the position of countries in the global financial markets, as credit rating agencies are currently considering taking increasing natural hazard risk into account when rating countries for their creditworthiness ${ }^{24}$. Our analyses with and without FPS demonstrate large differences in expected annual damage, making FPS an essential element for accurate assessment of absolute river flood risk metrics. A global FPS database can be set up through a careful revisiting of ongoing and established protection programmes and investments ${ }^{25}$, and analytical approaches ${ }^{10}$. The differences in results with and without FPS also show that adaptation measures have the potential to greatly reduce present and future flood damage. As the costs of flood protection are often lower than the benefits ${ }^{10}$, countries can often justify further investments in such adaptation measures. In particular, emerging economies in Southeast Asia also have much to gain from reducing exposure through urban planning, given that much of the risk increase estimated here is strongly impacted by projected socio-economic development. In African countries, increases in flood-induced economic impacts (\% GDP) are mainly driven by climate change, meaning that Africa's growing assets become increasingly exposed to floods. Long-term and sustainable investments in adaptation therefore become increasingly favourable in Africa. This may be achieved by moving more of the foreign disaster risk reduction aid from ad hoc disaster response, now consuming about $88 \%$ of total aid $^{26}$, to prevention.

Received 12 November 2014; accepted 11 November 2015; published online 21 December 2015

\section{References}

1. IPCC Managing the Risks of Extreme Events and Disasters to Advance Climate Change Adaptation (Cambridge Univ. Press, 2012); http://ipcc-wg2.gov/SREX/report

2. Hempel, S., Frieler, K., Warszawski, L., Schewe, J. \& Piontek, F A trend-preserving bias correction-the ISI-MIP approach. Earth Syst. Dynam. 4, 219-236 (2013).

3. O'Neill, B. C. et al. Meeting Report of the Workshop on The Nature and Use of New Socioeconomic Pathways for Climate Change Research (NCAR, 2012); https://www2.cgd.ucar.edu/sites/default/files/iconics/Boulder-WorkshopReport.pdf

4. Winsemius, H. C., Van Beek, L. P. H., Jongman, B., Ward, P. J. \& Bouwman, A. A framework for global river flood risk assessments. Hydrol. Earth Syst. Sci. 17, 1871-1892 (2013).

5. Ward, P. J. et al. Assessing flood risk at the global scale: Model setup, results, and sensitivity. Environ. Res. Lett. 8, 044019 (2013).

6. Hirabayashi, Y. et al. Global flood risk under climate change. Nature Clim. Change 3, 816-821 (2013)

7. NatCatSERVICE (Munich RE, accessed 15 August 2013).

8. Jongman, B., Ward, P. J. \& Aerts, J. C. J. H. Global exposure to river and coastal flooding-long term trends and changes. Glob. Environ. Change 22, 823-835 (2012)
9. Visser, H., Petersen, A. C. \& Ligtvoet, W. On the relation between weather-related disaster impacts, vulnerability and climate change. Climatic Change 125, 461-477 (2014).

10. Jongman, B. et al. Increasing stress on disaster-risk finance due to large floods. Nature Clim. Change 4, 264-268 (2014).

11. Brown, C., Meeks, R., Ghile, Y. \& Hunu, K. Is water security necessary? An empirical analysis of the effects of climate hazards on national-level economic growth. Phil. Trans. A 371, 20120416 (2013).

12. Pappenberger, F., Dutra, E., Wetterhall, F. \& Cloke, H. Deriving global flood hazard maps of fluvial floods through a physical model cascade. Hydrol. Earth Syst. Sci. 16, 4143-4156 (2012).

13. Sampson, C. C. et al. A high-resolution global flood hazard model. Wat. Resour. Res. 51, 7358-7381 (2015).

14. Ward, P. J. et al. Usefulness and limitations of global flood risk models. Nature Clim. Change 5, 712-715 (2015).

15. Milly, P. C. D., Wetherald, R. T., Dunne, K. A. \& Delworth, T. L. Increasing risk of great floods in a changing climate. Nature 415, 514-517 (2002).

16. Arnell, N. W. \& Gosling, S. N. The impacts of climate change on river flood risk at the global scale. Climatic Change http://dx.doi.org/10.1007/s10584-014-1084-5 (2014).

17. Ceola, S., Laio, F. \& Montanari, A. Satellite nighttime lights reveal increasing human exposure to floods worldwide. Geophys. Res. Lett. 41, 7184-7190 (2014).

18. Jongman, B. et al. Declining vulnerability to river floods and the global benefits of adaptation. Proc. Natl Acad. Sci. USA 112, E2271-E2280 (2015).

19. Hall, J. W. et al. Quantified scenarios analysis of drivers and impacts of changing flood risk in England and Wales: 2030-2100. Glob. Environ. Change 5, 51-65 (2003).

20. De Moel, H., Aerts, J. C. J. H. \& Koomen, E. Development of flood exposure in the Netherlands during the 20th and 21st century. Glob. Environ. Change 21, 620-627 (2011)

21. Taylor, K. E., Stouffer, R. J. \& Meehl, G. A. An overview of CMIP5 and the experiment design. Bull. Am. Meteorol. Soc. 93, 485-498 (2012).

22. Van Vuuren, D. P. et al. The representative concentration pathways: An overview. Climatic Change 109, 5-31 (2011).

23. Kron, W., Steuer, M., Löw, P. \& Wirtz, A. How to deal properly with a natural catastrophe database-analysis of flood losses. Nature Hazards Earth Syst. Sci. 12, 535-550 (2012).

24. Climate Change is Global Mega-Trend for Sovereign Risk, S↔P Report Says. Standard and Poor's Ratings Service (15 May 2014); http://www.standardandpoors.com/prot/ratings/articles/en/us/?article Type $=$ HTML\&assetID $=1245368455822$

25. Hallegatte, S., Green, C., Nicholls, R. J. \& Corfee-Morlot, J. Future flood losses in major coastal cities. Nature Clim. Change 3, 802-806 (2013).

26. Kellett, J. \& Caravani, A. Financing Disaster Risk Reduction: A 20 Year Story of International Aid (Global Facility for Disaster Reduction and Recovery and Overseas Development Institute, 2013); http://www.odi.org/sites/odi.org.uk/ files/odi-assets/publications-opinion-files/8574.pdf

27. World Bank List of Economies July 2011 (World Bank, 2011)

\section{Acknowledgements}

We are grateful for the co-funding from the EC FP7 funded project BASE (grant agreement number 308337). The research was also funded by a VENI grant from the Netherlands Organisation for Scientific Research (NWO), awarded to P.J.W. (grant no. 863.11.011). Finally, the research was funded as part of the Aqueduct Global Flood Analyzer project, via grant 5000002722 from the Netherlands Ministry of Infrastructure and the Environment. The project is convened by the World Resources Institute. Furthermore, we are grateful to the ISIMIP project team for making available the ISIMIP forcing data set. Finally, the authors wish to thank the Environment Agency of England and Wales and the Saxony State Office for Environment, Agriculture and Geology for the provision of the regional flood hazard maps, used for model benchmarking.

\section{Author contributions}

H.C.W. was responsible for computation of the flood hazard maps for all projections. H.C.W., M.F.P.B., L.P.H.B., B.J., P.J.W., A.B. and W.L. have established the global flood risk modelling framework used to perform the flood risk computations performed in the scope of this paper. A.B., J.C.J.H.A., W.L. and P.L.L. have derived the future exposure maps (population and GDP), B.J. and P.J.W. computed socio-economic risk. H.C.W. produced all graphs. All authors have contributed to the conceptualization and writing of the manuscript text.

\section{Additional information}

Supplementary information is available in the online version of the paper. Reprints and permissions information is available online at www.nature.com/reprints. Correspondence and requests for materials should be addressed to H.C.W.

\section{Competing financial interests}

The authors declare no competing financial interests. 